\title{
Stress-Strain Compression of AA6082-T6 Aluminum Alloy at Room Temperature
}

\author{
Alexandre da Silva Scari, Bruno Cesar Pockszevnicki, Jánes Landre Junior, \\ and Pedro Americo Almeida Magalhaes Junior \\ Department of Mechanical Engineering, Pontifical Catholic University of Minas Gerais, 30535-901 Belo Horizonte, MG, Brazil \\ Correspondence should be addressed to Alexandre da Silva Scari; alexandrescari@gmail.com
}

Received 16 June 2014; Revised 15 October 2014; Accepted 28 October 2014; Published 13 November 2014

Academic Editor: Hanxing Zhu

Copyright (C) 2014 Alexandre da Silva Scari et al. This is an open access article distributed under the Creative Commons Attribution License, which permits unrestricted use, distribution, and reproduction in any medium, provided the original work is properly cited.

\begin{abstract}
Short cylindrical specimens made of AA6082-T6 aluminum alloy were studied experimentally (compression tests), analytically (normalized Cockcroft-Latham criteria-nCL), and numerically (finite element analysis-FEA). The mechanical properties were determined with the stress-strain curves by the Hollomon equation. The elastic modulus obtained experimentally differs from the real value, as expected, and it is also explained. Finite element (FE) analysis was carried out with satisfactory correlation to the experimental results, as it differs about $1,5 \%$ from the damage analysis by the $\mathrm{nCL}$ concerning the experimental data obtained by compression tests.
\end{abstract}

\section{Introduction}

Mechanical properties of ductile materials are normally determined by tensile test. However, when the plastic deformation is the aim of the study, the compression test is the most suitable as it allows large deformations without the fracture of the specimen. For this test, the cylindrical specimen is the most adopted. However, in this case, the damage must be evaluated. Numerical analysis (i.e., finite element analysis-FEA) may be used to predict the damage for materials with elastic-plastic behavior. But, first, it is needed to perform classical model (analytical) and material (experimental) analysis.

Many studies were carried out concerning aluminum under axial compression; among them, Hopperstad et al. [1], Andrews et al. [2], and Gioux et al. [3] studied the compression of aluminum foams. Ferguson et al. [4] proposed an analytical model for predicting the mechanical properties of bimodal nanoaluminum alloys, concerning the grain size. Pled et al. [5] have done a numerical study of the crushing of circular aluminum tubes, with and without aluminum foam fillers. Han and Kim [6] proposed a new criterion for ductile fracture in sheet metal forming process. Luo et al. [7] performed isothermal compression tests of 7A09 aluminum alloy concerning solid cylindrical specimens. Rees [8] studied aluminum alloy sheets by plane strain compression. Wu et al. [9] determined the flow behavior and constitutive equations of 7050 aluminum alloy in isothermal compression. Kyačkaj et al. [10] studied the workability of AlMgSi aluminum alloy prepared by powder metallurgy, by means of analytical (damage) and numerical methods.

Some researches concerning damage of other metals have also been done, and some are listed here: Stefanik et al. [11] have determined the values of the normalized Cockcroft-Latham (nCL) for multi slight rolling based on tensile test of BSt500S steel. Xia et al. [12] studied the effects of temperature and strain rate on the damage value of AZ80 magnesium alloy. Alexandrov and Jeng [13] proposed a general method for the modified Cockcroft-Latham criterion at elevated temperatures. Quan et al. [14] evaluated the ductile fracture criteria for $42 \mathrm{CrMo}$ steel by compressions at different temperatures and strain rates. Landre et al. [15] contributed to the discussion of decoupled ductile fracture criteria and their use with finite element analysis, testing samples of AISI 1040 steel. 


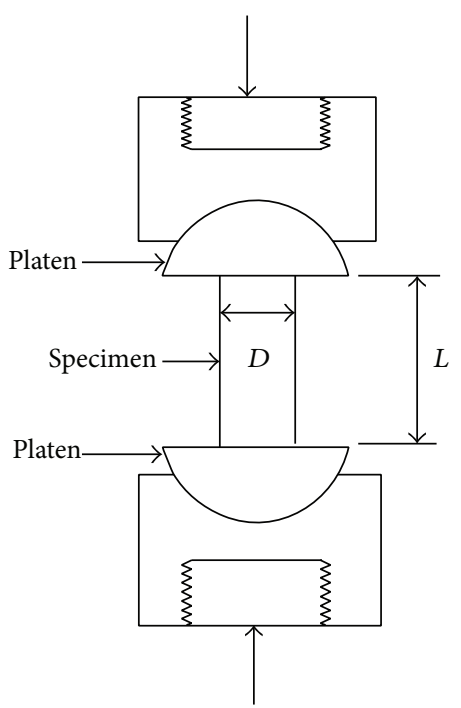

FIGURE 1: Cylindrical specimen in compression test between parallel plates. Source: adapted from [16].

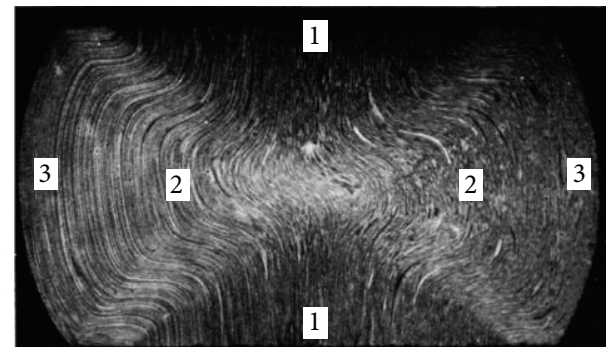

FIGURE 2: Illustration of barreling. Source: adapted from [17].

The goal of this paper is to evaluate and predict the damage of short solid cylindrical specimens made of an aluminum alloy, as just a few researches dealt with it. For this, the parameters of the Hollomon equation were obtained together with the normalized Cockcroft-Latham criterion (nCL) by the experimental data obtained by compression tests. FE analysis was performed and its result differs about $1,5 \%$ from the damage analysis by the $\mathrm{nCL}$, which shows that, once validated, FEA can be used to predict damage of elasticplastic materials.

\section{Literature Review}

2.1. Compression Test. The compression test consists of a specimen (normally with cylindrical shape) that is compressed between two parallel plates, with uniform velocity (see Figure 1). Mechanical properties such as the yield strength $\left(\sigma_{y}\right)$ and the elastic modulus $(E)$ can be obtained by this test. However, the ratio of initial length to diameter $\left(L_{0} / D\right)$ has great influence on the test results. According to ASTM [17], to accurately determine the elastic modulus in the compression test, it is necessary that $L_{0} / D \geq 8$ (long specimen). Short specimen presents $L_{0} / D \leq 2$.
Ductile materials in compression may present nonuniform transverse deformation, called barreling. It may be seen from Figure 2 that the specimen regions in contact with the plates present almost null plastic deformations (see number 1 on Figure 2), and the number 2 is where the plastic deformations occur. Also, the barreling is represented by the number 3 in Figure 2.

2.2. Plastic Deformation. The experimental data obtained by compression test can be described by the Hollomon equation (see (1)), where $\sigma$ is the true stress, $K$ is the strength coefficient, $\varepsilon$ is the true strain, and $n$ is the strain-hardening exponent:

$$
\sigma=K \cdot \varepsilon^{n}
$$

The coefficients in (1) can be obtained by power-law approximation of the experimental data obtained by compression test.

With the plate displacements and the corresponding forces, the strain can be calculated by three different ways: normal (2), logarithmic (3), and Lagrange equation (4):

$$
\begin{gathered}
\varepsilon=\frac{L-L_{0}}{L_{0}}, \\
\varepsilon=\ln \left(\frac{L}{L_{0}}\right), \\
\varepsilon=\frac{L^{2}-L_{0}^{2}}{2 \cdot L_{0}^{2}} .
\end{gathered}
$$

Assuming that the areas in contact with the plates (see Figure 1) remain constant, the actuating stress can be obtained with the ratio of the force $(F)$ to initial cross-section area $\left(A_{0}\right)$ as follows:

$$
\sigma=\frac{F}{A_{0}} .
$$

2.3. Ductile Fracture Criteria. According to Landre et al. [15], the damage criterion that best fits the workability of elasticplastic materials was proposed by Cockcroft and Latham (CL). It is based on a critical value of tensile strain per unit of volume and does not take into account the hydrostatic stress $\left(\sigma_{m}\right)$ because the large principal stress $\left(\sigma_{1 \max }\right)$ and $\sigma_{m}$ normally vary together. The normalized CL criterion (nCL) can be written as

$$
\frac{\sigma_{1 \max }}{K \cdot \varepsilon^{n-1}}=\mathrm{C}
$$

where

(i) $\sigma_{1 \text { max }}$ : large principal stress $[\mathrm{MPa}]$;

(ii) $K$ : strength coefficient $[\mathrm{MPa}]$;

(iii) $\varepsilon$ : true strain;

(iv) $n$ : strain-hardening exponent.

The values of $K$ and $\varepsilon$ on (6) are the same for (1). 
TABLE 1: Chemical composition (\%) of the aluminum alloy studied and the MATWEB reference.

\begin{tabular}{lcccccccccccc}
\hline Element & $\mathrm{Si}$ & $\mathrm{Mg}$ & $\mathrm{Mn}$ & $\mathrm{Fe}$ & $\mathrm{Cu}$ & $\mathrm{Zn}$ & $\mathrm{Ti}$ & $\mathrm{Cr}$ & $\mathrm{Pb}$ & $\mathrm{Sn}$ & $\mathrm{Al}$ \\
\hline Specimen & 1.12 & 0.24 & 0.46 & 0.21 & 0.017 & 0.002 & 0.023 & 0.005 & 0.001 & 0.000 & 97.89 \\
MATWEB & $0.70-1.3$ & $0.60-1.2$ & $0.40-1.0$ & $\leq 0.50$ & $\leq 0.10$ & $\leq 0.20$ & $\leq 0.10$ & $\leq 0.25$ & $\leq 0.05$ & $\leq 0.05$ & $95.2-93.3$ \\
\hline
\end{tabular}

TABLE 2: Displacements applied on the specimens.

\begin{tabular}{lll}
\hline Displacement $[\mathrm{mm}]$ & \multicolumn{2}{c}{ Specimens } \\
\hline 0.50 & $1 \mathrm{a}$ & $1 \mathrm{~b}$ \\
0.75 & $2 \mathrm{a}$ & $2 \mathrm{~b}$ \\
1.50 & $3 \mathrm{a}$ & $3 \mathrm{~b}$ \\
2.50 & $4 \mathrm{a}$ & $4 \mathrm{~b}$ \\
4.00 & $5 \mathrm{a}$ & $5 \mathrm{~b}$ \\
\hline
\end{tabular}

\section{Materials and Methods}

3.1. Experimental Tests. The cylindrical specimens were made of AA6082-T6 aluminum alloy. Its chemical composition was determined by laboratory (chemical analysis) and is presented on Table 1, which also presents the reference values of MATWEB [19]. According to MATWEB [19], this alloy presents yield stress $\sigma_{y}=250 \mathrm{MPa}$, ultimate stress $\sigma_{u}=$ $290 \mathrm{MPa}$, elastic modulus $E=70 \mathrm{GPa}$, and hardness Brinell $\mathrm{HB}=90$.

It may be seen from Table 1 that the magnesium concentration $(0.24 \%)$ of the specimens is a little lower than the minimum indicated by MATWEB (0.60\%-1.20\%). Magnesium is added to an aluminum alloy in order to improve its strength.

For the compression tests, the plate displacement velocity was constant and equal to $2 \mathrm{~mm} / \mathrm{min}$. Ten specimens were tested, all of them with diameter $D=15.78 \mathrm{~mm}$ and average initial length $L_{0}=28.7 \mathrm{~mm}$. Thus, $L_{0} / D=1.82$, which represents short specimens. The displacements adopted for each specimen are presented in Table 2 .

After the tests, with the flange displacements and the respective forces applied for each instant of time, some information may be calculated (i.e., strains and tensions) and the yield stress can be determined. Also, the stress-strain curves for each specimen were obtained and, with the powerlaw approximation, the coefficients of the Hollomon equation (see (1)) were determined along with the critical values of the nCL.

Figure 3 presents one of the specimens before the compression test.

3.2. Finite Element Analysis (FEA). The finite element (FE) model consists of hexahedral elements with $1.0 \mathrm{~mm}$ length. The software adopted was Hypermesh (preprocessor), Abaqus (solver), and Hyperview (postprocessor). Assuming that the lower and upper faces present only axial displacement in the compression test, in the FE model, the lower face was restricted (all degrees of freedom (DOFs)) and a plate with contact elements was used to apply the compression force in the upper face. Its value is $75526 \mathrm{~N}$ according to specimen $4 b$ (see Table 3 ). The elastic modulus considered was the real one $(70 \mathrm{GPa})$ Figure 4 presents the FE model analyzed.

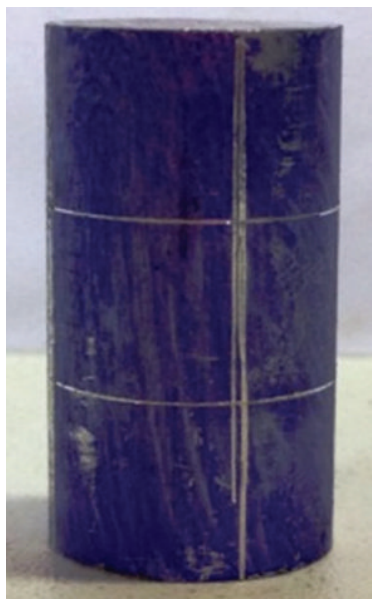

FIGURE 3: Cylindrical specimen before compression test.

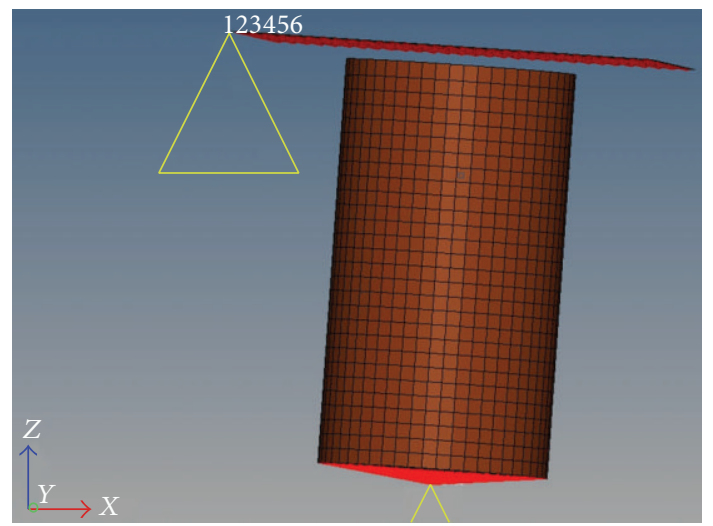

Figure 4: FE model.

\section{Results and Discussion}

4.1. Experimental Tests. Table 3 presents the experimental results summary for each specimen subjected to compression test and also the calculation results (strain, stress, and elastic modulus). It can be seen from Table 3 that $\varepsilon_{\text {normal }}$ (2) present intermediate values among $\varepsilon_{\text {logarithmic }}$ (3) and $\varepsilon_{\text {Lagrange }}(4)$. So, $\varepsilon_{\text {normal }}$ was used to calculate the elastic modulus.

The stress-strain curves obtained experimentally are presented in Figure 5.

According to Table 3 and Figure 5,

(i) specimen la did not enter the plasticity region;

(ii) the average elastic modulus is $16 \mathrm{GPa}$, lower than the real value $(70 \mathrm{GPa})$. This lower value was expected and is due to the $L_{0} / D=1.82$ ratio, according to [17]; 
TABLE 3: Experimental results summary.

\begin{tabular}{|c|c|c|c|c|c|c|c|c|}
\hline Specimen & $\Delta L[\mathrm{~mm}]$ & $F[\mathrm{~N}]$ & Stress $[\mathrm{MPa}]$ & $\varepsilon_{\text {normal }}$ & $\varepsilon_{\text {Lagrange }}$ & $\varepsilon_{\text {logarithmic }}$ & $E[\mathrm{MPa}]$ & $\sigma_{y}[\mathrm{MPa}]$ \\
\hline la & 0.078 & 44525 & 227.7 & 0.01750 & 0.01735 & 0.01766 & 13008.2 & 227.7 \\
\hline $1 b$ & 0.027 & 49714 & 254.2 & 0.01464 & 0.01453 & 0.01475 & 17368.0 & 252.2 \\
\hline $2 a$ & 0.187 & 56542 & 289.1 & 0.02380 & 0.02352 & 0.02409 & 13323.5 & 245.5 \\
\hline $2 b$ & 0.198 & 57570 & 294.4 & 0.02341 & 0.02313 & 0.02369 & 17006.2 & 228.7 \\
\hline $3 a$ & 0.866 & 64384 & 329.2 & 0.04957 & 0.04834 & 0.05084 & 15697.4 & 217.4 \\
\hline $3 b$ & 0.921 & 70400 & 360.0 & 0.05116 & 0.04985 & 0.05252 & 18178.4 & 250.4 \\
\hline $4 a$ & 1.753 & 76888 & 393.1 & 0.08245 & 0.07905 & 0.08605 & 16920.9 & 253.0 \\
\hline $4 \mathrm{~b}$ & 1.612 & 75526 & 386.2 & 0.07799 & 0.07495 & 0.08120 & 14040.0 & 261.4 \\
\hline $5 a$ & 3.317 & 77916 & 398.4 & 0.13820 & 0.12865 & 0.14873 & 17049.7 & 239.7 \\
\hline $5 b$ & 3.012 & 84035 & 429.7 & 0.12996 & 0.12152 & 0.13922 & 15654.3 & 249.2 \\
\hline
\end{tabular}

TABLE 4: Average coefficients of the Hollomon equation obtained experimentally.

\begin{tabular}{lcc}
\hline Strain & $\begin{array}{c}\text { Strength } \\
\text { coefficient, } K \\
{[\mathrm{MPa}]}\end{array}$ & $\begin{array}{c}\text { Strain-hardening } \\
\text { exponent, } n\end{array}$ \\
\hline$\varepsilon_{\text {normal }}$ & 587.5 & 0.203 \\
$\varepsilon_{\text {logarithmic }}$ & 593.1 & 0.208 \\
$\varepsilon_{\text {Lagrange }}$ & 585.5 & 0.205 \\
\hline
\end{tabular}

TABLE 5: Comparison among aluminum alloys properties.

\begin{tabular}{lccc}
\hline Aluminum alloy & $K[\mathrm{MPa}]$ & $n$ & $\begin{array}{c}\text { Ultimate stress, } \\
\sigma_{u}[\mathrm{MPa}]\end{array}$ \\
\hline AA6082 T6 & 588.7 & 0.205 & 290 \\
AA2024 T4 $^{\mathrm{a}}$ & 806 & 0.200 & 476 \\
AA6111 $^{\mathrm{b}}$ & 504 & 0.270 & 272 \\
\hline
\end{tabular}

${ }^{*}$ Source: ${ }^{\mathrm{a}}$ Dowling [18]; ${ }^{\mathrm{b}} \mathrm{Han}$ and Kim [6].

(iii) the yield stress varied from $217.4 \mathrm{MPa}$ to $261.4 \mathrm{MPa}$, consistent with the real value of $250 \mathrm{MPa}$; also, these values agree with the results obtained by Hopperstad et al. [1];

(iv) strain calculated with the Lagrange equation (see (4)) leads to the lowest results.

With the stress-strain curves presented in Figure 5, powerlaw approximations were done in order to determine the coefficients of the Hollomon equation (1). The average values are presented in Table 4. Yet, the power-law approximation results are of high quality, as $R^{2}=0.999$ for each regression made.

According to Table 4,

(i) the average value of the strength coefficient $(K)$ is 588.7 MPa;

(ii) the average value of the strain-hardening coefficient (n) is 0.205 .

Comparing the values presented in Table 4 with the AA2024-T4 properties presented by Dowling [18] and Han and Kim [6] (see Table 5), the strain-hardening coefficient

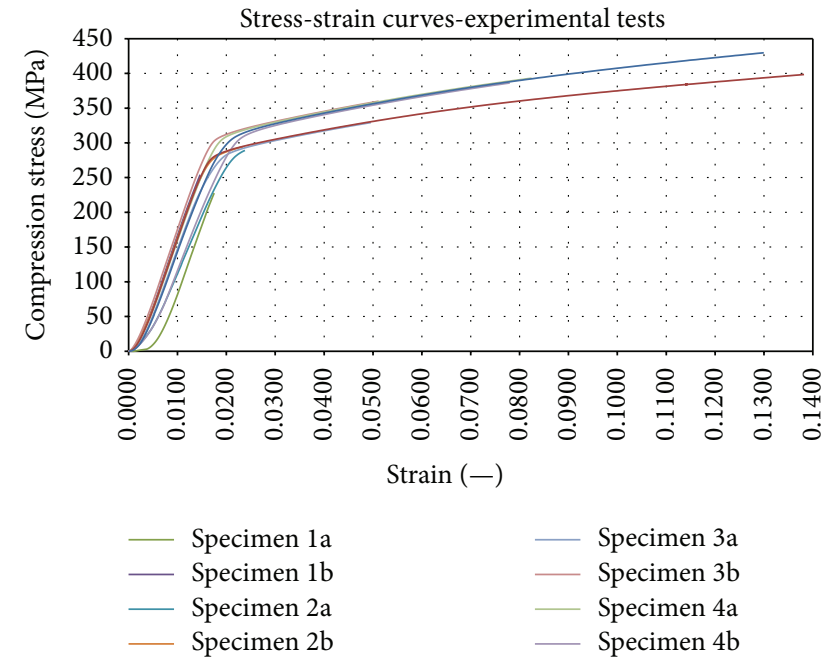

FIGURE 5: Stress-strain curves from compression tests.

$(n)$ is almost the same (2.5\% different). Also, the strength coefficient $(K)$ increases with the strength of the aluminum alloy (or hardness).

Yet, according to Hosford [20], the strength coefficient $(K)$ lies between $400 \mathrm{MPa}$ and $550 \mathrm{MPa}$. Also, common values of the strain-hardening coefficient $(n)$ remain between 0.20 and 0.30. Comparing with Table 5, the values of $K$ are lower with respect to AA6082-T6 and AA2124-T4 alloys but the values of $n$ are in accordance.

Rees [8] obtained $E=75 \mathrm{GPa}$ for AC 120 and HE30TF aluminum alloys with the compression of sheets instead of cylindrical specimens. Although this difference is in the elastic modulus, the strain-hardening coefficient $(n)$ for the AC 120 aluminum alloy obtained by the same author was 0.218 , very similar to the value obtained in this work $(0.205$, see Table 5).

4.2. FEA Results. The FEA results for the specimen $4 b$ are presented in Figure 6 and in Table 6. The minimum principal stress obtained is $-458.9 \mathrm{MPa}$. Also, the plastic equivalent strain is 0.09822 . Comparing these results with those presented in Table 3, it may be seen that 


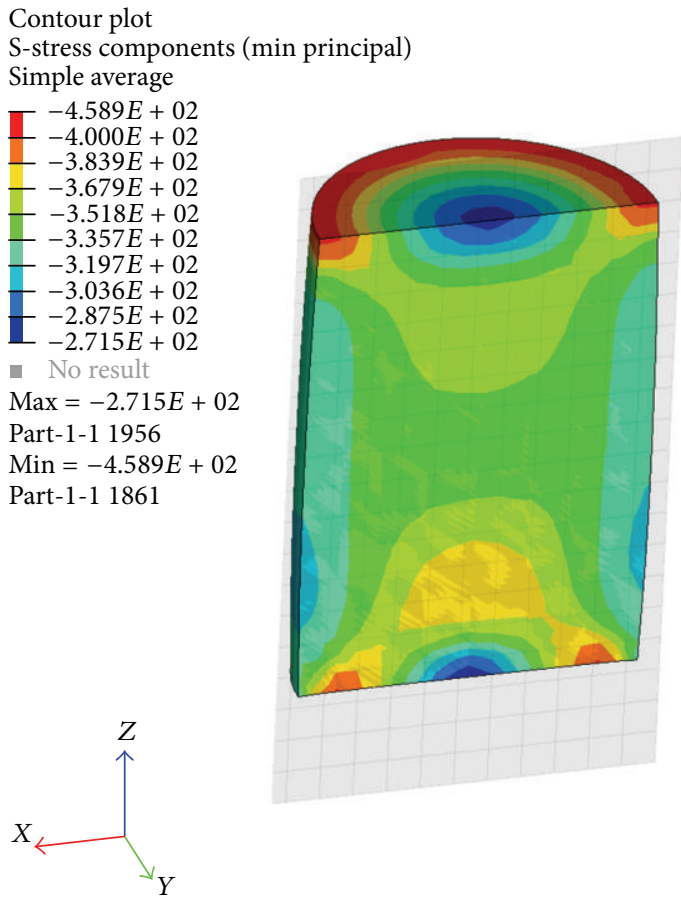

(a)

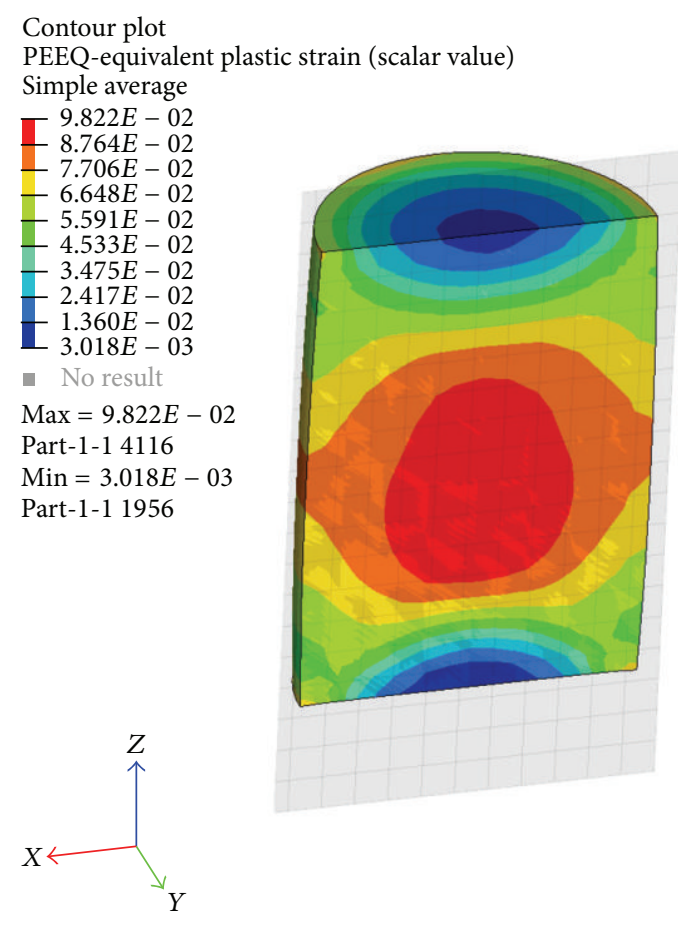

(b)

FIGURE 6: FEA results: (a) minimum principal stress; (b) plastic equivalent strain-specimen $4 b$.

TABLE 6: FEA results.

\begin{tabular}{lc}
\hline Minimum principal stress [MPa] & Plastic equivalent strain \\
\hline-458.9 & 0.09822 \\
\hline
\end{tabular}

(i) the minimum principal stress obtained $(-458.9 \mathrm{MPa})$ is $6.8 \%$ greater than the specimen $5 b$ result $(-429.5 \mathrm{MPa})$;

(ii) the plastic strain obtained $(0.09822)$ is $14.1 \%$ greater than the logarithmic strain presented by the specimen $4 a(0.08605)$;

(iii) Figure 6 is in accordance with Figure 2.

4.3. Damage Results. Table 7 presents the results concerning the nCL criterion for each specimen subjected to compression test. The nCL curves obtained experimentally are presented in Figure 7.

According to the above results,

(i) as the compression tests were stopped before fracture, the curves on Figure 7 did not present asymptotic behavior;

(ii) specimen $5 b$ presented the highest value of $\mathrm{nCL}$ $(0.144128$, see Table 7$)$ as it was subjected to the highest compression force (84035 N, see Table 3);

(iii) the orange value of plastic equivalent strain (PEEQ) on Figure 6(b) varies from 0.07706 to 0.08764 . Comparing this maximum (0.08764) with the maximum nCL obtained for specimen $4 b(0.086313$, see Table 7$)$,

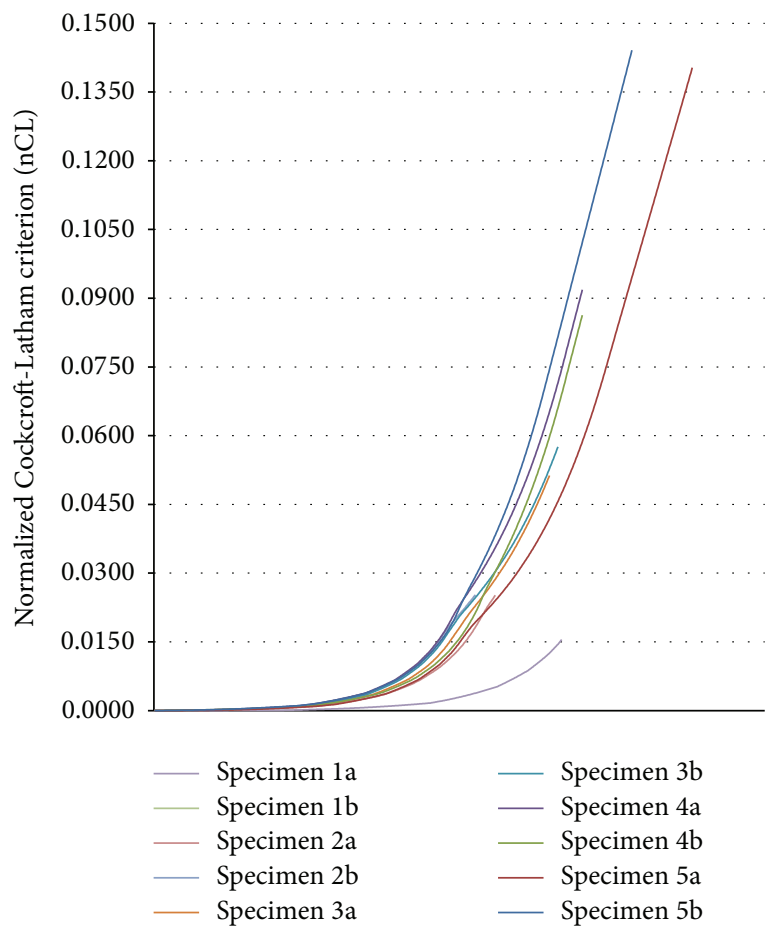

FigURE 7: nCL curves from compression tests.

the numerical value is $1.54 \%$ greater than the experimental result. As FE formulation has some known intrinsic errors, the difference of $1.54 \%$ between the 


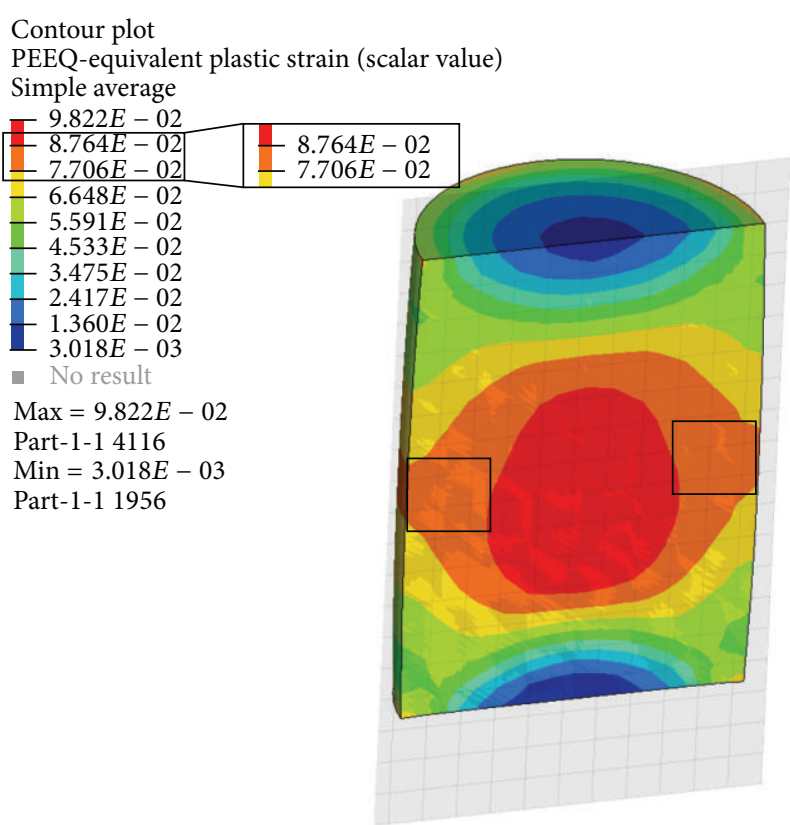

FIGURE 8: Orange regions highlighted from Figure 6(b).

TABLE 7: nCL criterion results summary.

\begin{tabular}{lc}
\hline Specimen & nCL $[-]$ \\
\hline $1 \mathrm{a}$ & 0.015512 \\
$\mathrm{lb}$ & 0.015027 \\
$2 \mathrm{a}$ & 0.025153 \\
$2 \mathrm{~b}$ & 0.025272 \\
$3 \mathrm{a}$ & 0.051318 \\
$3 \mathrm{~b}$ & 0.057543 \\
$4 \mathrm{a}$ & 0.091840 \\
$4 \mathrm{~b}$ & 0.086313 \\
$5 \mathrm{a}$ & 0.140321 \\
$5 \mathrm{~b}$ & 0.144128 \\
\hline
\end{tabular}

mentioned results shows a satisfactory correlation between experimental and numerical analysis.

Figure 8 illustrates the orange region of Figure 6(b).

\section{Conclusions}

The ratio $L_{0} / D=1,82$ is not suitable for determining the elastic modulus $(E)$, as the average value of $E$ obtained was $16 \mathrm{GPa}$ and right value is $70 \mathrm{GPa}$. According to ASTM [17], the ideal ratio for that purpose is $L_{0} / D=8$. Yet, different shapes in compression (instead of cylindrical specimens) may lead to more accurate values of the elastic modulus.

The average yield stress obtained $(242.5 \mathrm{MPa})$ is $3.0 \%$ lower than the value informed by MATWEB [19] (250 MPa). This difference may be due to the magnesium concentration on this aluminum alloy $(0.24 \%)$ which is lower than the minimum specified for this alloy $(0.60 \%)$.
The coefficients of the Hollomon equation obtained by power-law approximation are in accordance with the literature for the AA6082-T6 aluminum alloy. Also, the values of $K$ and $n$ were used to calculate nCL for each specimen.

FEA results presented satisfactory correlation to the experimental tests as the difference, concerning specimen $4 b$, is about $1,5 \%$ from the damage analysis by the nCL criterion, which shows that, once validated, FEA can be used to predict damage of elastic-plastic materials.

\section{Conflict of Interests}

The authors declare that there is no conflict of interests regarding the publication of this paper.

\section{Acknowledgments}

The authors would like to thank the support of the "Pontificia Universidade Catolica de Minas Gerais (PUC Minas)" and the "Coordenação de Aperfeiçoamento de Pessoal de Nível Superior (CAPES)."

\section{References}

[1] O. S. Hopperstad, M. Langseth, and T. Tryland, "Ultimate strength of aluminium alloy outstands in compression: experiments and simplified analysis," Thin-Walled Structures, vol. 34, no. 4, pp. 279-294, 1999.

[2] E. Andrews, W. Sanders, and L. J. Gibson, "Compressive and tensile behaviour of aluminum foams," Materials Science and Engineering A, vol. 270, no. 2, pp. 113-124, 1999.

[3] G. Gioux, T. M. McCormack, and L. J. Gibson, "Failure of aluminum foams under multiaxial loads," International Journal of Mechanical Sciences, vol. 42, no. 6, pp. 1097-1117, 2000.

[4] J. B. Ferguson, M. Tabandeh-Khorshid, P. K. Rohatgi, K. Cho, and C.-S. Kim, "Predicting tensile and compressive mechanical properties of bimodal nano-aluminum alloys," Scripta Materialia, vol. 72-73, pp. 13-16, 2014.

[5] F. Pled, W. Yan, and C. Wen, "Crushing modes of aluminium tubes under axial compression," in Proceedings of the 5th Australasian Congress on Applied Mechanics, December 2007.

[6] H. N. Han and K.-H. Kim, "A ductile fracture criterion in sheet metal forming process," Journal of Materials Processing Technology, vol. 142, no. 1, pp. 231-238, 2003.

[7] J. Luo, M. Q. Li, and D. W. Ma, "The deformation behavior and processing maps in the isothermal compression of 7A09 aluminum alloy," Materials Science and Engineering A, vol. 532, pp. 548-557, 2012.

[8] D. W. A. Rees, "Plane strain compression of aluminium alloy sheets," Materials \& Design, vol. 39, pp. 495-503, 2012.

[9] B. Wu, M. Q. Li, and D. W. Ma, "The flow behavior and constitutive equations in isothermal compression of 7050 aluminum alloy," Materials Science and Engineering A, vol. 542, pp. 79-87, 2012.

[10] T. Kyačkaj, R. Kočiško, J. Tiža et al., "Application of workability test to SPD processing," Archives of Metallurgy and Materials, vol. 58, no. 2, pp. 407-412, 2013.

[11] A. Stefanik, H. Dyja, and S. Mróz, "Determination of the critical value of normalized Cocroft-Latham criterion during multi 
slight rolling based on tensile test," Archives of Metallurgy and Materials, vol. 56, no. 2, pp. 543-550, 2011.

[12] Y.-F. Xia, G.-Z. Quan, and J. Zhou, "Effects of temperature and strain rate on critical damage value of AZ80 magnesium alloy," Transactions of Nonferrous Metals Society of China, vol. 20, no. 2, pp. s580-s583, 2010.

[13] S. Alexandrov and Y.-R. Jeng, "An efficient method for the identification of the modified Cockroft-Latham fracture criterion at elevated temperature," Archive of Applied Mechanics, vol. 83, no. 12, pp. 1801-1804, 2013.

[14] G.-Z. Quan, G.-C. Luo, A. Mao, J.-T. Liang, and D.-S. Wu, "Evaluation of varying ductile fracture criteria for $42 \mathrm{CrMo}$ steel by compressions at different temperatures and strain rates," The Scientific World Journal, vol. 2014, Article ID 579328, 10 pages, 2014.

[15] J. Landre, A. Pertence, P. R. Cetlin, J. M. C. Rodrigues, and P. A. F. Martins, "On the utilisation of ductile fracture criteria in cold forging," Finite Elements in Analysis and Design, vol. 39, no. 3, pp. 175-186, 2003.

[16] M. Meyers and K. Chawla, Mechanical Behavior of Materials, Cambridge University Press, New York, NY, USA, 2nd edition, 2009.

[17] ASTM, "Standard test methods of compression testing of metallic materials at room temperature," ASTM E9-09, 2009.

[18] N. E. Dowling, Mechanical Behavior of Materials, Pearson Prentice Hall, Upper Saddle River, NJ, USA, 3rd edition, 2007.

[19] "Material property data-MATWEB. Mechanical properties of AA6082 T6 aluminum alloy," http://www.matweb.com/ search/DataSheet.aspx?MatGUID=fad29be6e64d4e95a241690flf6eleb7.

[20] W. F. Hosford, Mechanical Behavior of Materials, Cambridge University Press, New York, NY, USA, 2005. 

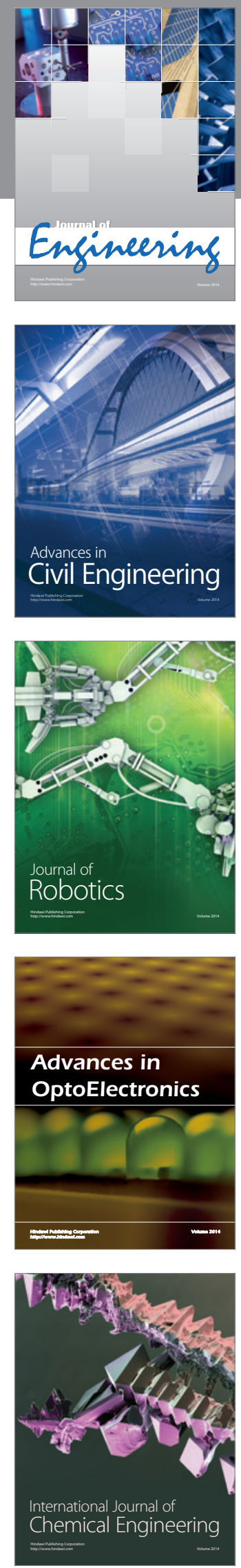

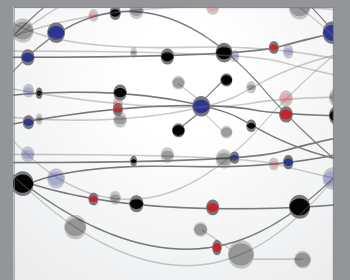

The Scientific World Journal
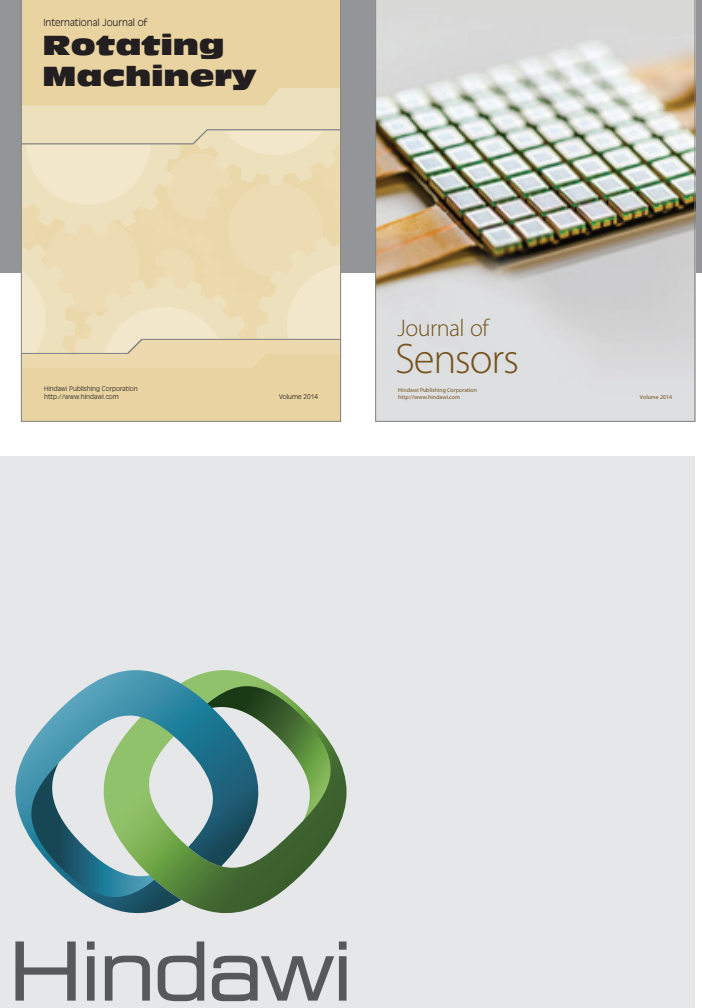

Submit your manuscripts at http://www.hindawi.com
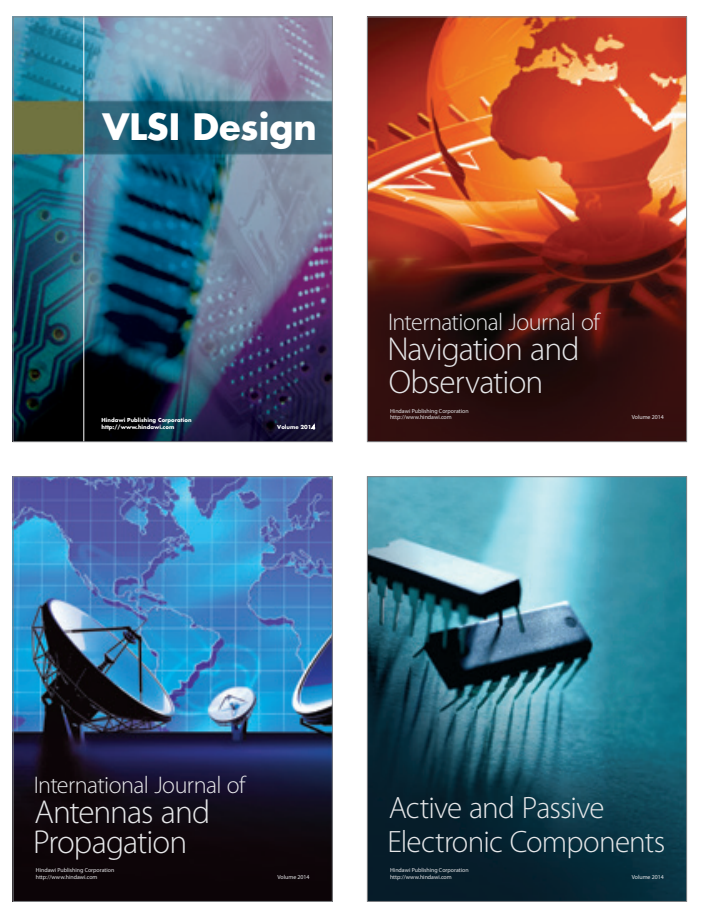
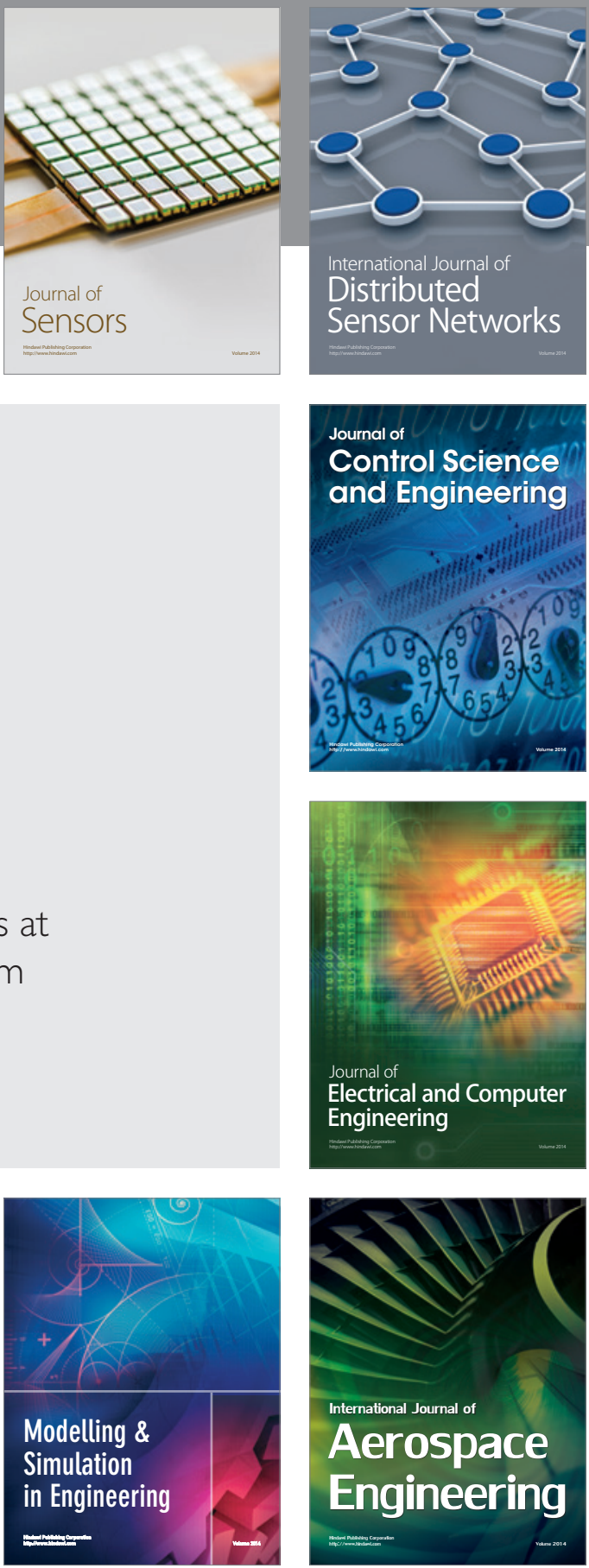

Journal of

Control Science

and Engineering
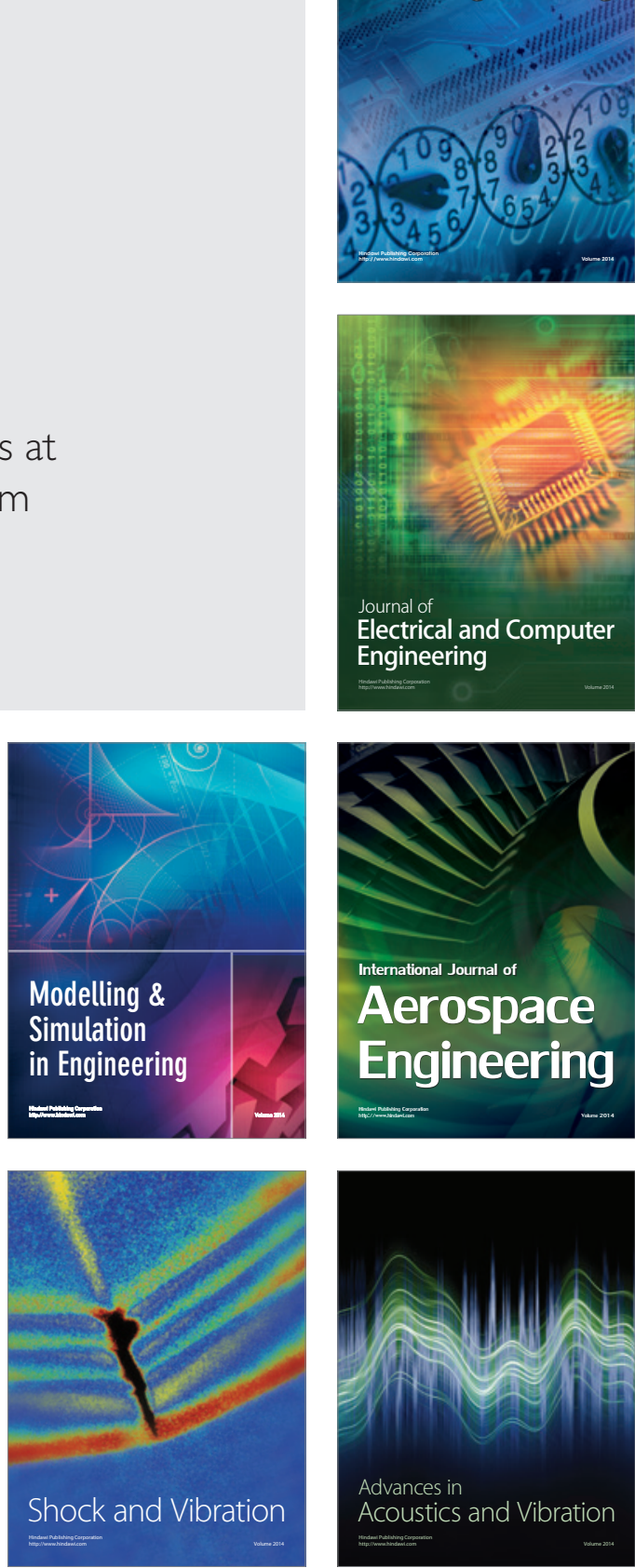